\title{
Problems Encountered by Mobile Teachers Assigned in Tandag City Division, Surigao del Sur: A Case Study
}

\author{
Jondy M. Arpilleda
}

\author{
Ph.D., Surigao del Sur State University, Tandag City, Philippines \\ Jondyarpilleda@gmail.com
}

\begin{abstract}
This research study used both the qualitative and quantitative research designs to investigate the problems encountered by the mobile teachers in Tandag City Division. This study specifically aimed to: (1) describe the mobile teacher' socio-demographic and professional profile;(2)investigate their teaching performance; and (3) discover the problems they encountered in the implementation of the program.

The data revealed that most of the mobile teachers assigned in the far-flung barangays of Tandag City are male teachers. Five of them are permanent and only one is contractual. Majority of them are graduates of Bachelor in Elementary Education and they are beginning teachers. The data reveal that they need more training and seminars on the pedagogy of Alternative Learning System and other related topics.In terms of teaching performance, they have a very satisfactory rating in the three indicators namely: personal attribute, competence and professional development.
\end{abstract}

Four problems emerged: lack of instructional materials; delayed release of allowances; absence of permanent learning center and other facilities; and, irregular attendance of ALS students. They also complained the lack of support from local officials and their huge class size.

Keywords - Problems encountered, Mobile Teachers, Alternative Learning System.

\section{INTRODUCTION}

Literacy is fundamental to the achievement of every individual in both his/her career ambition and quality of life. Literacy per se is more than a basic reading ability, but rather an indication of "how adults use written information in society" (McMullen, 2008). The world is full of challenges. Thus, in a competitive society - children, youth and adults alike, should be equipped with strong literacy skills, which are necessary to acquire a good job, decent earnings and access to quality learning opportunities.
In the Philippines, the Out-of-School Children (OSC), Out-of-School Youth (OSYs) and Out-of-School Adults (OSAs) comprise a huge number of Filipinos who are most affected to this menace due to lack of educational opportunities. As revealed in the Country Profile for the EFA

Global Monitoring Report 2008, Education for All 2015, sixteen million two hundred eighty-two thousand three hundred forty-three $(16,282,343)$ out-of-school Filipino citizens, who comprised $20 \%$ of the 82 million total of the Philippine Population (2004) are Out-of-School youth. The 2004 NSO Report cited "poverty" as the primary contributor to the high growth of OSY.

Hence, the Philippine government through the Department of Education has implemented the Alternative Learning System (ALS), which is exemplified by Executive Order No. 356 "Renaming Non-formal Education to Alternative Learning System (ALS), Republic Act No. 7165, Presidential Proclamation No. 480, s 1989, EFA 2015. This program is considered as a crucial component of Philippine Education to provide every individual with access to quality basic education as envisioned in the Education for All (EFA) 2015 Philippine Plan of Action, and specifically the reduction of illiteracy rate.

Records show that the ALS program has been implemented in the entire country for almost 18 years now since it started in 1999. However, the result revealed that only few succeeded to meet the required competencies for accreditation to be granted equivalent rights like the students completing the elementary and secondary education level in this informal educational system. Many studies also revealed that that there are many problems that both the ALS students and the mobile teachers encountered. Specifically, in the study of Mercado (2015) titled "Problems encountered in the ASL program in Tanauan City" disclosed that students suffered problems in instruction, assessment and evaluation. He also found out 
that facilities like classrooms and instructional materials like textbooks, manuals, etc. are lacking. Moreover, mobile teachers revealed that they have meager salaries or honorarium and other allowances .

Another significant study was that of Pinca (2015),

titled “The Mobile Teachers' Profile, Competencies, Problems and in the Department of Education, Division of Northern Samar, Philippines." She found out that the major problems met by the mobile teachers in Northern Samar Division were lack of community-based instructional materials, delayed release of travel allowance and absence of permanent room during the conduct of the learning sessions. With these above-mentioned information, the researcher is prompted to undertake a similar study in the ALS program of the Department of Education in Tandag City Division, Surigao del Sur. This study sought to investigate the socio-demographic and professional profile of the mobile teachers and to examine whether these ALS teachers have experienced the same problems mentioned by Pinca and Mercado.

Objectives of this Study
The main thrust of this research was to discover the problems met by the mobile teachers in Tandag City

Division, Surigao del Sur. Specifically, it sought to:

1. describe the socio-demographic profile of ALS teachers in terms of age, sex, and educational qualification;

2. determine their professional profile in terms of their field of specialization, seminars and training attended, and length of service;

3. investigate their teaching performance; and,

4. discover the problems in the implementation of the program as experienced by the ALS teachers, education program supervis or and specialist.

\section{METHODS}

This research study used the qualitativequantitative research design involving all the Mobile teachers, supervis or and program specialist who were assigned in Tandag City Division, which covers the 21 barangays (refer to Figure 1). The Tandag City Division is located at the heart of the city. The research locale, the areas of the Alternative Learning System department, of this study is managed by the program supervisor.

\section{GEOGRAPHICAL MAP of TANDAG CITY}

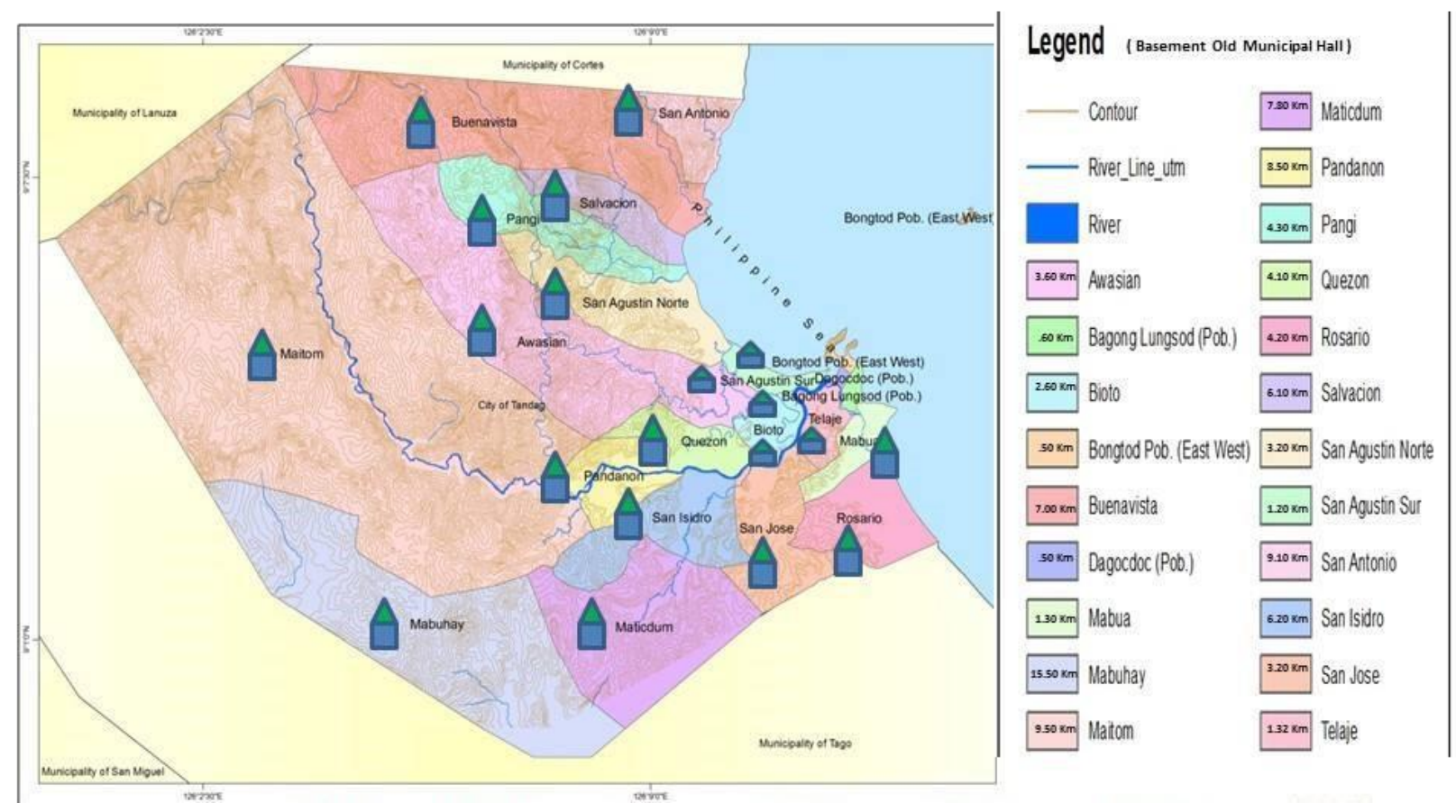

Fig.1: Geographical Map of the 21 Barangays in Tandag City 
Of the 21 barangays, 4 barangays are not accessible by jeepneys and public utility vehicles (PUV's). These include barangay Maitum, Hitaob, San Antonio and Mabuhay. The latter is the furthest; around 15 kilometers away fromthe city proper and is only accessible by habal-habal.

The researcher conducted both Focus-GroupDiscussion and one-on-one interviews with the six mobile teachers. He also administered a questionnaire to obtain the ALS teachers socio-demographic and professional profile. As regards the performance of the mobile teachers, their supervisor and program specialist were interviewed and were asked for their performance scores, which the rating scheme was patterned to the Department of Education. The responses from the FGD and the data obtained from interviews and the questionnaire were interpreted through frequency counts, ranking and percentages.

\section{RESULTS AND DISCUSSIONS} Socio-demographic Profile of the Alternative Learning System (ALS) Teachers

The data in Table 1 reveal that fifty percent $(50 \%)$ of the teacher-respondents were on their early adulthood or they belong to the young professionals. Being young, they have the physical stamina in commuting from one barangay to another, and even reaching far-flung barangays where they are assigned. The other half which had been assigned before in those far barangays are now assigned in the city proper.

Table.1: Socio-demographic Profile of theALS Teachers

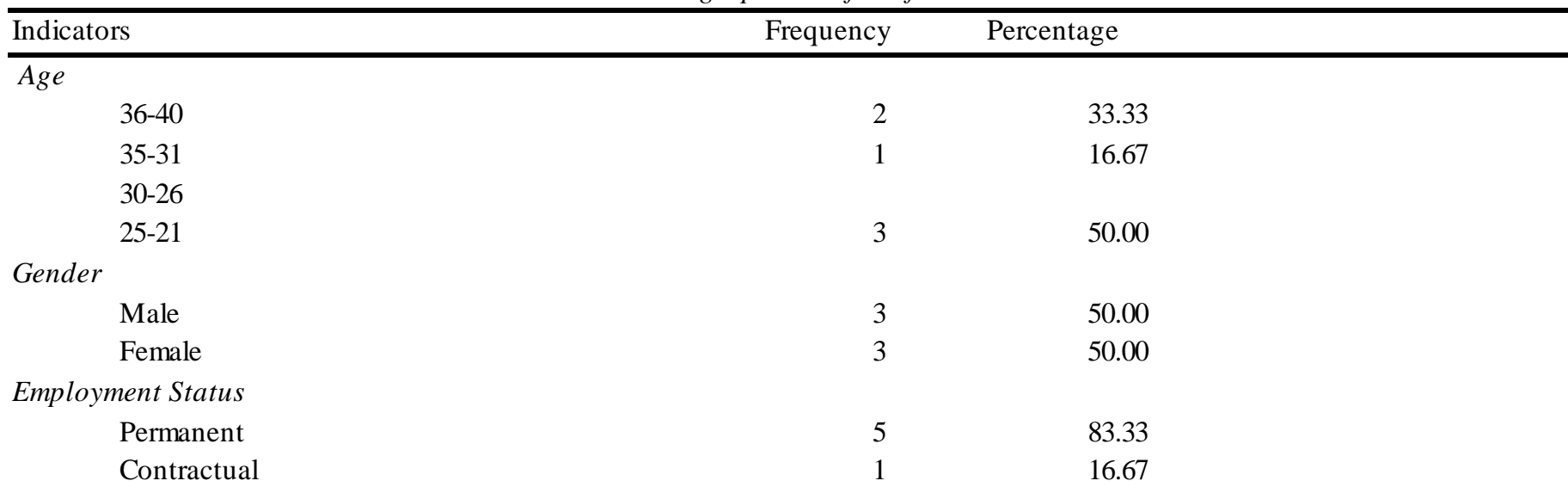

As to gender, half of the mobile teachers are males and the other half are females. Yet, majority of the ones assigned in the far-flung barangays are the male teachers. This could be explained by the notion that male teachers are better fit in reaching remote areas. This finding is the same as that of Pinca's (2016) and Mercado's (2015) studies which revealed that the newly hired male teachers are being assigned to teach in distant barangays. This is so because they have the physical stamina in commuting far areas.When it comes to employment status, five (5) of the mobile teachers are permanent and only one holds a contractual status. This suggests that only one teacher does not receive regular salary, benefits and allowances afforded to all ALS teachers.

\section{Professional Profile of the Mobile Teachers}

In terms of educational qualification, a majority of the respondents are graduates of Bachelor in Elementary Education and one Bachelor of Science in Secondary Education. Only two(2) out of six (6) are pursuing master's degree and had gained masters units. Also, none of them specializes on Alternative Learning System (ALS) or any nearest allied degree program. This connotes that all of them do not have formal training how to teach ALS classes.

Table.2: Professional Profile of the Mobile Teachers

\begin{tabular}{lll}
\hline Indicators & Frequency & Percentage \\
\hline Educational Qualification & 2 & 33.33 \\
BEED/BSED with master's degree & 4 & 66.67 \\
BEED/BSED & & \\
Field of Specialization & \\
\hline
\end{tabular}


Generalist

Mathematics

Length of teaching experience

11 years and more

6-10 years

5 years and less

Number of Days of Attendance to Training/Seminars

11 days and more

6-11 days

5 days and less

\section{5}

2

4

2

2

2
83.33

16.67

33.33

66.67

33.33

33.33

33.33
When it comes to the mobile teachers' length of service, majority of the respondents $(66.67 \%)$ have been teaching for five (5) years or less. This means that the majority of them are less experienced teachers and only two $(33.33 \%)$ are considered seasoned teachers. This data suggests they are still learning the ropes of teaching students in the ALS program.

Finally, the data reveal that only two (2) teacherrespondents have attended seminars/training on ALS pedagogy and other related topics for more than 11 days; another 2teachers have attended for 6-10 days; and another 2 have attended for 5 days or even less. These figures mean that theyshould be exposed to more in-service training and seminars on ALS learning and teaching, module-making and other related topics.

\section{Performance of the Mobile Teachers}

Table 3 revealed thatfive (5) out of six (6) mobile teachers in Tandag City Division obtained a Very
Satisfactory rating on their performance as evaluated by their students, peers and supervisor. There were three indicators which comprised their performance: personal attribute, competence and professional development. Only one got a satisfactory rating. This data connotes that generally the mobile teachers are doing well with their job. In the data given by their supervisor, these teachers obtained outstanding rating on personal attributes which comprise good interpersonal relations, flexibility, participative leadership and exemplary conduct. However, when it comes to adoption of high standards of grading and teaching and in transforming illiterate learners to basic literacy, half of them got satisfactory rating. This means that these mobile teachers need to improve their teaching strategies, learning tasks and assessment methods.Some of the reasons which could be attributed to this matter is that majority of them need more seminar and training (refer to Table 2) on ALS and other very important topics like andragogy or science of teaching adults.

Table.3: Teaching Performance of the Mobile Teachers

\begin{tabular}{lccc}
\hline Rating & Indicator & Frequency & Percentage \\
\hline $8.6-10.00$ & Outstanding & & \\
$6.6-8.5$ & Very Satisfactory & 5 & 83.33 \\
$4.6-6.5$ & Satisfactory & 1 & 16.67 \\
\hline
\end{tabular}

On the other hand, half of the mobile teachers were rated satisfactory on professional development. This finding could be attributed to the fact that three of the mobile teachers are newly hired and they do not have yet sufficient in-service training and seminars attended and they are not enrolled in graduate studies. During the FGD, teachers A, $\mathrm{B}$, D disclosed that their training and seminars on ALS related topics are not adequate enough to their needs. Teacher C specifically, the contractual employee, revealed that she had only attended a training once. On the other hand, Teachers B and D said that it is hard for them to enroll in graduate studies because they sometimes have classes during weekends to compensate some meetings that they missed because of the conflict of schedule with their students.

\section{Problems Encountered by the Mobile Teachers}

It can be seen in Table 4 that four problems are common among the six mobile teachers: lack of instructional materials, delayed release of allowance, absence of permanent learning center and other facilities and irregular attendance of ALS students. Teacher B and E specifically revealed that they just downloaded the learning guide and module in the DepEd website as their source or reference. 
This finding is the same as that of Pinca's (2016) and Mercado's (2015) study where both the students and mobile teachers complained about the availability of the Instructional Materials. Hence, the mobile teachers opted to research for suitable topics on the internet. Teacher A, on the other hand,revealed that the module is sometimes confusing and there is a mismatch of the teaching guide and the downloadable module in the internet.

Moreover, they also unanimously complained on the delay of their allowances. Teachers A, B and F specifically shared that they could have provided their students with sufficient number of copies (photocopies of their topics and learning activities) if their teaching allowance had been released much earlier. One big problem also that confronts them is the absence of permanent learning center or classroom. Teachers B and C specifically pointed out that they always transfer from one place to another every class session. Teacher B addedthat he has to ask one of his students to be the host of their class session. Meaning, they are going to hold classes at his student's house. Teacher $\mathrm{C}$ also disclosed that he has difficulty teaching his class because the waiting shed they are using is too small to accommodate all his students.

Table.4: Problems Encountered by Mobile Teachers

\begin{tabular}{lccl}
\hline Indicators & Frequency & TeachersRank & \\
\hline Lack of instructional materials & 6 & A,B,C,D,E,F & 1 \\
Delayed Release of Allowance & 6 & A,B,C,D,E,F & 1 \\
Absence of permanent learning center and other facilities & 6 & A,B,C,D,E,F & 1 \\
Irregular attendance of ALS students & 6 & A,B,C,D,E,F & 1 \\
Lack of support from local officials & 5 & A,C,D,E,F & 4.5 \\
Class size & 5 & A,B,C,E,F & 4.5 \\
Risky learning sites & 3 & B,D,E & 7 \\
Very far learning sites (assigned barangays) & 2 & B,E & 8.5 \\
Attitudes of ALS students & 2 & C,E & 8.5 \\
\hline
\end{tabular}

On the other hand, the mobile teachers also revealed that they have problems gathering all their students because of their irregular attendance. Teachers A, B, C, and F said that they have to adjust with their students' availability or schedule because some of them are working in the department stores and other shops and some have to go to their farms. Hence, this has prompted them to conduct classes even during weekends to compensate the missed sessions. Teachers D and Esaid they even conduct one-onone tutorials with their students especially those slow learners.

The Alternative Learning System (ALS) teachers also revealed that they lack support from the local officials and they have problems with their class size. Teachers B specifically revealed that he sometimes conducts classes in a waiting shed, in the house of his students and under a mango tree. These accounts are also supported by their supervisor. He personally observed that the some local officials in Tandag city did not initiate any action even though they have been sending letters of request for a dialogue and request for the provision of one Community Learning Center (CLC). However, he shared somegood news that finally the congressman of the $1^{\text {st }}$ District of
Surigao del Sur has promised a provision of one CLC this year.

In terms of class size, five of the mobile teachers divulged that during the first months of enrolment, they usually have big class size which inadvertently has caused another burden especially in the provision of instructional materials. But ironically, this number will dwindle down during the middle of the school year. In other words, others will just drop out of their school. Meanwhile, teachers B, D and $\mathrm{E}$ who are assigned in far barangays like Hitaob, Banahaw Maitum and Mabuhay disclosed that they have hard time adjusting and reaching to their assigned areas. They decried the time travel and the vicious roadsthey have to pass by. Teacher B specifically, who is assigned in barangay Hitaob has to cross nine (9) rivers just to reach the place and there are only few habal-habal, a mode of transportation, that will reach there. He said, "I have to stay for two to five days in that barangay so that a two-week session will be covered by my class. Finally, teachers $\mathrm{C}$ and E complained about the attitude of the students. They observed that some of them are not focused and they are only good at the start but after sometime, they will lose the interest in going to classes. On the other hand, teacher E recalled that some of his students, especially the Indigenous 
People (IP) would meanly reproach him if he had missed a class and if he had failed to inform them in advance. Some of his students too would ask for something like cigarette each time he will go at their barangay for a class. Sadly, this has become customary to them.

\section{SUMMARY AND CONCLUSIONS}

Fifty percent of the Alternative Learning System (ALS) teachers assigned in Tandag City Division were on their early adulthood and are males. This is the case because male teachers are better fit in reaching remote areas, especially those areas which are considered to be "hot spots" for the military men. When it comes to employment status, five of them are permanent and only one is contractual.

In terms of educational qualification, none of them is a graduate of Alternative Learning System course. Five (5) finished Bachelor in Elementary Education and one inBachelor of Science in Secondary Education major in mathematics. Though two are pursuing a master's degree, none of them specializes on Alternative Learning System (ALS). Aside from that, these teachers are less experienced and they have not attended a lot of seminars and training on ALS and other related topics. Clearly these information imply that they need more training and exposure on the pedagogy of Alternative Learning System and other relevant matters.

As to teaching performance, majority of these teachers got a Very Satisfactory rating in the three specified indicators: personal attribute, competence and professional development. This connotes that they are doing well with their job even though they are new at it and it is not their field of expertise. However, fifty percent of them were rated satisfactory on professional development. This finding validates the fact that they are newly hired and they do not have sufficient training and seminars on ALS pedagogy and other topics.

There are four problems which are common to them: lack of instructional materials, delayed release of allowance, absence of permanent learning center and other facilities and irregular attendance of ALS students. Themobile teachers also complained on the delay of their allowances. Some of them disclosed that they could have provided their students with sufficient number of copies (photocopies of their topics and learning activities) if their teaching allowance had been released much earlier.

On the other hand, they also have problems on the availability of classrooms. They always transfer from one place to another every class session and their learning sites are not conducive for learning. Hence, this has prompted them to conduct classes even during weekends to www.ijels.com compensate the missed sessions. Two problems got equal footing:the lack support from local officials and the class size.They revealed that the some LGU officials (in the barangay level) did not provide them with permanent room or venue. This aggravated their problems on th class size (or their number of students).

\section{RECOMMENDATIONS}

Based on the findings and conclusions of this study, the following recommendations are suggested:

1. The mobile teachers may ask the assistance of their supervisor to expedite the release of their allowance so that they can produce the needed instructional materials for their classes. Moreover, during their school break, the supervisor could propose an in-house workshop on instructional materials preparation among the mobile teachers;

2. The Tandag City Division should conduct a quarterly seminar-workshop on ALS, andragogy of education and other related topics to equip the mobile teachers with all the knowledge and skills on teaching the students. This will also upgrade their competence and professional aspect;

3. The Tandag City Division could create a linkage with Higher Education Institutions (HEIs) like Surigao del Sur State University in terms of facilities and manpower support; and,

4. Another study may be conducted to look into the variables which were not included in this study.

\section{REFERENCES}

[1] McMullen, Kathryn (2008). Literary Skills of Canadian across the ages: Fewer low achievers, fewer higher achievers. "Education Matters: Insights on Education, Learning and Training in Canada", 4 no.6 Catalogue no. 81-004XIE. Ottawa: Statistics Canada.

[2] Mercado, Ivan Perry (2015). Problems Encountered in the Alternative Learning System in Tanauan City. International Journal for Education and Social Sciences. $\begin{array}{lllll}\text { Volume } & 2, & \text { No. } & 8 . & \text { August }\end{array}$ 2015.http://www.ijessnet.com/wpcontent/uploads/2015/09/5.pdf

[3] Pinca, Estrellita (2015). The Mobile Teachers' Profile, Competencies, Performance and Problems in the Department of Education, Division of Northern Samar, Philippines. International Journal of Scientific and Technology Research. Volume 4, Issue 12, December 2015.https://www.scribd.com/document/298485585/The -Mobile-Teachers-Profile-Competencies-PerformanceAnd-Problems-In-The-Department-Of-EducationDivision-Of-Northern-Samar-Philippines-pdf 